\title{
Sternotomy closure using rigid plate fixation: a paradigm shift from wire cerclage
}

\author{
Keith B. Allen ${ }^{1}$, Kyle J. Icke ${ }^{2}$, Vinod H. Thourani ${ }^{3}$, Yoshifumi Naka ${ }^{4}$, Kendra J. Grubb ${ }^{5}$, John Grehan ${ }^{6}$, \\ Nirav Patel ${ }^{7}$, T. Sloane Guy ${ }^{8}$, Kevin Landolfo ${ }^{9}$, Marc Gerdisch $^{10}$, Mark Bonnell ${ }^{11}$ \\ ${ }^{1}$ Saint Luke's Mid America Heart Institute, Kansas City, MO, USA; ${ }^{2}$ Zimmer Biomet, Jacksonville, FL, USA; ${ }^{3}$ MedStar Washington Hospital \\ Center, Washington, DC, USA; ${ }^{4}$ Columbia University Medical Center, New York, NY, USA; ${ }^{5}$ University of Louisville, Louisville, KY, USA; ${ }^{6}$ Allina \\ Health, Saint Paul, MN, USA; ${ }^{7}$ Lenox Hill Hospital, New York, NY, USA; ${ }^{8}$ Temple University, Philadelphia, PA, USA; ${ }^{9}$ Mayo Clinic, Jacksonville, \\ FL, USA; ${ }^{10}$ Franciscan St. Francis Health, Indianapolis, IN, USA; ${ }^{11}$ University of Toledo, Toledo, OH, USA \\ Correspondence to: Keith B. Allen, MD. Saint Luke's Mid America Heart Institute, 4320 Wornall Rd, Medical Plaza II, Suite 50, Kansas City, MO \\ 64111, USA. Email: kallen2340@aol.com.
}

Background: Rigid plate fixation (RPF) is the cornerstone in managing fractures and osteotomies except for sternotomy, where most cardiac surgeons continue to use wire cerclage (WC). Results of a multicenter randomized trial evaluating sternal healing, sternal complications, patient reported outcome measures (PROMs), and costs after sternotomy closure with RPF or WC are summarized here.

Methods: Twelve US centers randomized 236 patients to either RPF $(n=116)$ or WC $(n=120)$. The primary endpoint, sternal healing at 6 months, was evaluated by a core laboratory using computed tomography and a validated 6-point scale (greater scores represent greater healing). Secondary endpoints assessed through 6 months included sternal complications and PROMs. Costs from the time of sternal closure through 90 days and 6 months were analyzed by a health economic core laboratory.

Results: RPF compared to WC resulted in better sternal healing scores at $3(2.6 \pm 1.1$ vs. $1.8 \pm 1.0 ; \mathrm{P}<0.0001)$ and 6 months $(3.8 \pm 1.0$ vs. $3.3 \pm 1.1 ; \mathrm{P}=0.0007)$ and higher sternal union rates at $3[41 \%(42 / 103)$ vs. $16 \%$ (16/102); $\mathrm{P}<0.0001]$ and 6 months [80\% (81/101) vs. 67\% (67/100); $\mathrm{P}=0.03]$. There were fewer sternal complications with RPF through 6 months $[0 \%(0 / 116)$ vs. $5 \%(6 / 120) ; \mathrm{P}=0.03]$ and a trend towards fewer sternal wound infections [0\% (0/116) vs. 4.2\% (5/120); $\mathrm{P}=0.06]$. All PROMs including sternal pain, upper extremity function (UEF), and quality-of-life scores were numerically better in RPF patients compared to WC patients at all follow-up time points. Although RPF was associated with a trend toward higher index hospitalization costs, a trend towards lower follow-up costs resulted in total costs that were $\$ 1,888$ less at 90 days in RPF patients compared to WC patients (95\% CI: $-\$ 8,889$ to $\$ 4,273 ; \mathrm{P}=0.52$ ) and $\$ 1,646$ less at 6 months (95\% CI: $-\$ 9,127$ to $\$ 4,706 ; \mathrm{P}=0.61$ ).

Conclusions: Sternotomy closure with RPF resulted in significantly better sternal healing, fewer sternal complications, improved PROMs and was cost neutral through 90 days and 6 months compared to WC.

Keywords: Sternotomy; fixation; plating; closure; healing

Submitted Mar 29, 2018. Accepted for publication May 24, 2018.

doi: 10.21037/acs.2018.06.01

View this article at: http://dx.doi.org/10.21037/acs.2018.06.01

\section{Introduction}

Median sternotomy is the most common osteotomy and is performed annually in the United States in over 500,000 patients (1). While rigid plate fixation (RPF) remains the cornerstone in managing osteotomies and fractures in order to prevent nonunion, reduce complications, and improve patient outcomes, most cardiac surgeons continue to use wire cerclage (WC) for sternotomy closure (2).

Although wires are effective at sternal approximation, 
they do not provide rigid fixation and are inadequate at preventing sternal movement following surgery (3-8). While studies have shown that RPF improves sternal stability and healing and reduces sternal complication rates compared with WC, adoption of RPF by cardiac surgeons has been limited by the perception that outcomes with $\mathrm{WC}$ are adequate and their initial cost is low compared to RPF (9-14).

This article summarizes the previously reported results from a prospective, randomized, single-blinded, multicenter trial that compared RPF to WC $(9,15)$. The primary endpoint of the study was to evaluate sternal healing using computed tomography (CT) comparing RPF to WC at 6 months. Secondary endpoints included sternal complications and patient reported outcomes including pain, upper extremity function (UEF), and quality of life (QOL). Additionally, healthcare related costs were examined using a 90-day global bundle and out to 180 days.

\section{Methods}

\section{Patients}

This trial enrolled 236 patients undergoing cardiac surgery at 12 US centers between March 2013 and June 2015 (9). Institutional review board approval was obtained along with informed consent from each patient. This study was sponsored by Zimmer Biomet (Jacksonville, FL) and registered on clinicaltrials.gov (NCT01783483).

Patients undergoing elective cardiac surgery via a median sternotomy who were admitted to the hospital within 24 hours of surgery were eligible for enrollment. Exclusion criteria included a $B M I \geq 40$, severe COPD, active infection, NYHA Class IV heart failure, dialysis dependent renal failure, chronic steroid/narcotics use, the use of nonresorbable hemostatic agents (i.e., bone wax) or any intraoperative condition that would require or preclude the use of either WC or RPF (e.g., poor bone quality, bleeding, surgical complications, or off-midline sternotomies). Patients were randomized at the time of sternal closure to either RPF or WC in a 1:1 ratio. Patients were blinded to the method of sternal closure, with blinding efficacy assessed at each follow-up interval.

\section{Sternotomy closure technique}

The technique for RPF (SternaLock Blu, Zimmer Biomet, Jacksonville, FL) with important caveats is illustrated in Figure 1 and has been previously reported $(9,12,16)$. Briefly, the sternal halves were reduced with three wires, muscle/ fascia was elevated off the sternum at the location of plate placement, and plates are contoured as needed to rest flush with the sternum (Figure 1A,B,C). Self-drilling cancellous screws of appropriate length to engage the anterior and posterior sternal cortex were selected and locked into the plates (Figure 1D) with one plate on the manubrium and two plates on the sternal body (Figure $1 E$ ). If emergent reentry is required, standard wire cutters can be used to cut the cross sections of the plates spanning the sternotomy (Figure $1 F$ ). In patients randomized to $\mathrm{WC}$, a minimum of 6 wires was pre-specified; however, the wiring configuration was per surgeon preference.

\section{Data collection}

Sternal healing was determined by a radiology core laboratory (University of Chicago, Chicago, IL) using CT and a validated method that has been described previously (Figure 2) $(9,12,17)$. Briefly, axial CT slices from five $a$ priori-defined anatomic locations were selected by a core laboratory radiologist. To preserve blinding, one core laboratory radiologist attempted to select CT slices that did not reveal which method of closure was used, then two additional radiologists independently scored each location using a 6-point scale (greater scores represent greater healing and sternal union was pre-specified and defined as a mean score of $\geq 3)(9,12,17)$. Sternal complications were defined as any adverse event related to the sternal closure and tracked through 6 months, and included deep or superficial wound infections as defined by the Society of Thoracic Surgeons (STS).

Postoperative sternal pain was evaluated daily during the index hospital admission and at 3 weeks, 6 weeks, 3 months, and 6 months using a 10-point numerical rating pain scale. Pain intensity was evaluated at rest, then following forced coughing and ranked from 0 to 10 ( 0 was no pain and 10 representing the worst possible pain). A postoperative pain management protocol was utilized by all centers for both arms of the study, which included patient-controlled analgesics followed by oral hydrocodone/acetaminophen.

QOL (SF-36 v2, QualityMetric, Lincoln, RI) and UEF were evaluated at baseline, discharge, 3 weeks, 6 weeks, 3 months, and 6 months. The SF-36 measures functional status and wellbeing from the patient's perspective and includes two summary scores: (I) a physical component score which measures physical functioning, bodily pain, general health, and limitations due to physical problems, and (II) a 

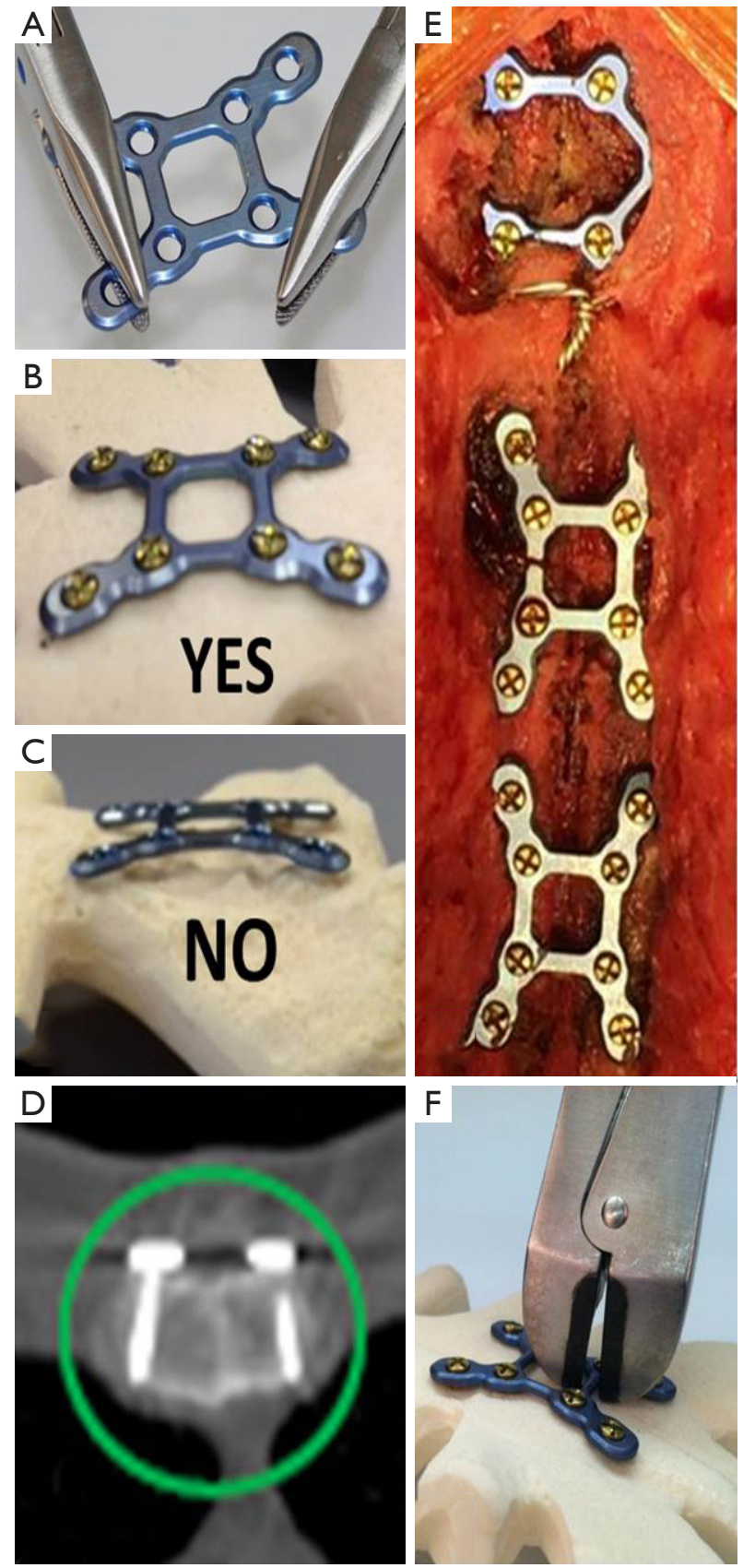

Figure 1 The technique for rigid plate fixation involves first reducing the sternal halves with three wires. Muscle/fascia is elevated off the sternum at the location of plate placement and plates are contoured (A) as needed to rest flush with the sternum (B,C). Self-drilling cancellous screws of appropriate length to engage the anterior and posterior sternal cortex (D) are selected with one plate on the manubrium and two plates on the sternal body (E). Should emergent re-entry be required, the sections of the plate spanning the sternotomy can be easily cut with standard wire cutters $(\mathrm{F})$. mental component score which measures limitations due to emotional problems, social functioning, vitality, and mental health. The scores are scaled such that the US population mean is 50 with a standard deviation of 10 (higher scores indicate better status). UEF was assessed using the upper extremity functional index (UEFI) which is a validated 20item questionnaire used for quantifying UEF in performing normal daily activities in patients with musculoskeletal problems (18). Respondents rate their difficulty in performing upper extremity activities using a 5 -point scale $(0$ to 4), with lower scores representing greater difficulty.

A health economic core laboratory (Saint Luke's Mid America Heart Institute, David J. Cohen, MD) performed the economic analysis using methods similar to those applied to drug-eluting coronary stents and transcatheter versus surgical aortic valve replacement (19-21). Analysis of total healthcare costs (not charges) from the time of sternal closure through 6-month follow-up was pre-specified. Additional post hoc analysis of healthcare costs in the context of a 90-day global episodic payment model was also performed.

\section{Statistical analysis}

Analysis was on an intent-to-treat basis and pre-specified. The primary endpoint, mean CT scan sternal healing score at 6 months, was evaluated with a mixed model for repeated measures (MMRM, SAS Proc Mixed, Version 9.4; SAS Institute, Inc., Cary, NC). Analysis of sternal healing scores was completed after adjusting for 15 baseline covariates (BMI, age, smoking, peripheral artery disease, chronic lung disease, sex, race, hypertension, cerebrovascular disease, diabetes, previous sternotomy, CABG, valve, operating room time, and closure time). Multiple linear regression with backward stepwise regression using the same 15 covariates was used to determine independent risk factors for reduced sternal healing scores at 3 and 6 months. In order to determine the potential impact of sternal healing on PROMs, the relationship between mean CT scan sternal healing score and postoperative sternal pain was evaluated using logistic regression (15). Exact logistic regression was used to determine the variables predictive of sternal complications and infections. Covariates considered included method of closure (RPF or WC) and known risk factors for sternal complications including diabetes, renal failure, smoking status, chronic obstructive pulmonary disease (COPD), previous sternotomy, bilateral internal mammary artery (BIMA), age, sex, and body mass index (BMI). Continuous data, including scores for PROMs, were summarized and 


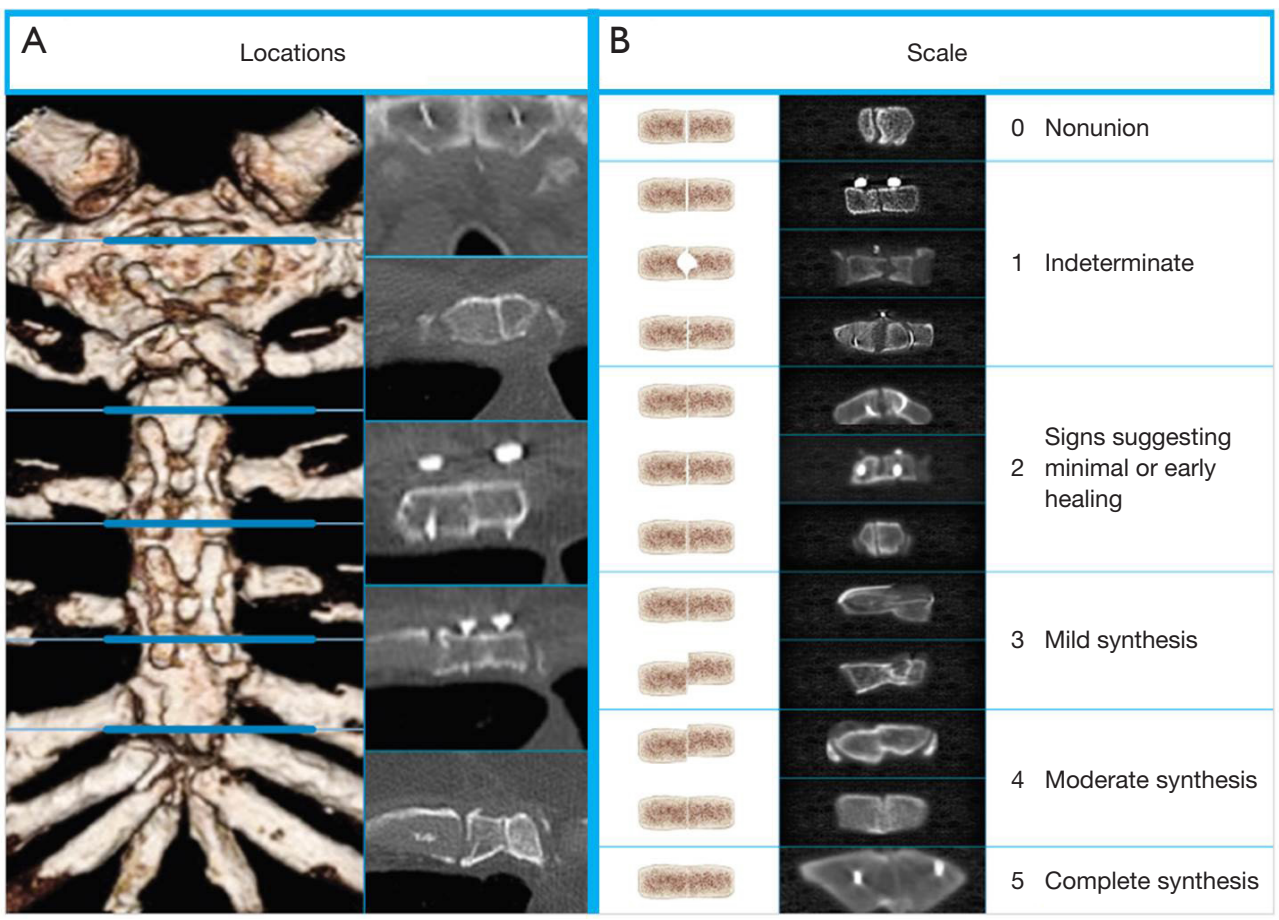

Figure 2 Computed tomography methodology for evaluating the primary endpoint, sternal healing. Five axial sections were selected from $a$ priori-defined anatomic locations (A) and then scored independently by 2 radiologists via a 6-point scale (B).

presented as a mean \pm standard deviation and compared using $t$-tests. Categorical data, including complication rates and the percentage of patients without sternal pain or functional limitations, are summarized as a number (\%) and compared using two-sided Fisher's exact tests.

Healthcare costs from the time of sternal closure through 90 days and 6 months follow-up are described as mean values and were compared using non-parametric bootstrapping (1,000 replicates) (22). For patients with incomplete followup, measures of resource utilization and cost were imputed for the missing time period based on their daily rates during the immediately previous time period.

\section{Results}

\section{Demographic data}

Enrollment included 236 patients randomized to RPF $(n=116)$ or WC $(n=120)$. Groups were similar with respect to baseline characteristics, preoperative/intraoperative risk factors for sternal complications, and surgical procedures performed (Table 1). Patient follow-up and blinding at 6 months was $88 \%(203 / 231)$ and $77 \%(152 / 198)$, respectively, and is detailed in Table 2 . In patients randomized to $W C$, a mean of $7.8 \pm 0.8$ wires per patient was utilized.

\section{Sternal healing}

RPF resulted in significantly better CT derived sternal healing scores compared to WC at both $3(2.6 \pm 1.1 \mathrm{vs}$. $1.8 \pm 1.0 ; \mathrm{P}<0.0001)$ and 6 months $(3.8 \pm 1.0$ vs. $3.3 \pm 1.1$; $\mathrm{P}=0.0007)$. In addition, RPF compared to $\mathrm{WC}$ resulted in greater rates of sternal union at 3 months $[41 \%(42 / 103) v s$. $16 \%(16 / 102) ; \mathrm{P}<0.0001]$ and 6 months $[80 \%(81 / 101) v s$. 67\% (67/100); $\mathrm{P}=0.03]$.

Patient demographics independently associated with reduced sternal healing scores at both 3 and 6 months included increased age (per 10 years), increasing BMI (per $5 \mathrm{~kg} / \mathrm{m}^{2}$ ), and current smoking (Tables 3,4). After risk adjustment for these factors, RPF (versus WC) was associated with an increase in sternal healing scores at both 3 months (0.68; 95\% CI: $0.41-0.95: \mathrm{P}<0.0001)$ and 6 months (0.47; 95\% CI: 0.19-0.75: $\mathrm{P}=0.001)$.

\section{Sternal complications}

Sternal complications through 6 months occurred 
Table 1 Patient demographics, risk factors for sternal complications, and intraoperative variables

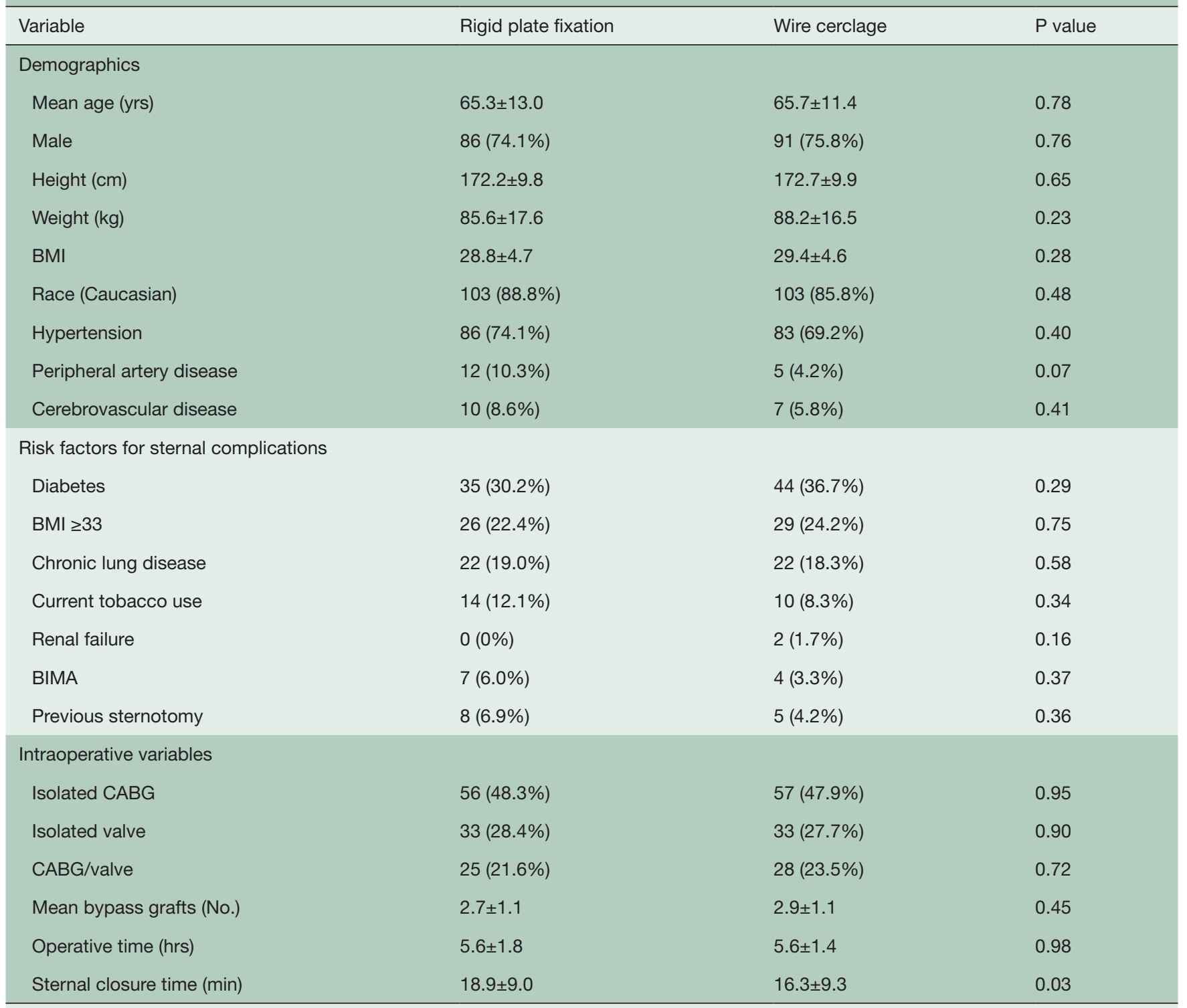

BMI, body mass index; BIMA, bilateral internal mammary artery; CABG, coronary artery bypass graft.

Table 2 Patient follow-up and blinding

\begin{tabular}{lllll}
\hline Follow-up interval & Rigid plate fixation & Wire cerclage & Overall & Patient blinding maintained \\
\hline 3 weeks & $97 \%(111 / 114)$ & $93 \%(110 / 118)$ & $95 \%(221 / 232)$ & $83 \%(179 / 215)$ \\
6 weeks & $96 \%(110 / 114)$ & $98 \%(116 / 118)$ & $97 \%(226 / 232)$ & $82 \%(185 / 226)$ \\
3 months & $90 \%(103 / 114)$ & $92 \%(108 / 117)$ & $91 \%(211 / 231)$ & $80 \%(171 / 213)$ \\
6 months & $90 \%(102 / 114)$ & $86 \%(101 / 117)$ & $88 \%(203 / 231)$ & $77 \%(152 / 198)$ \\
\hline
\end{tabular}

Note: patient follow-up excludes deaths. A total of 2 patients died in the rigid plate fixation group and 3 patients died in the wire cerclage group. 


\begin{tabular}{|c|c|c|c|c|c|c|}
\hline \multirow[b]{2}{*}{ Sternal healing } & \multicolumn{3}{|l|}{3 months } & \multicolumn{3}{|l|}{6 months } \\
\hline & $\begin{array}{l}\text { Rigid plate fixation } \\
(n=103)\end{array}$ & $\begin{array}{l}\text { Wire cerclage } \\
(n=102)\end{array}$ & $P$ value & $\begin{array}{l}\text { Rigid plate fixation } \\
(n=101)\end{array}$ & $\begin{array}{l}\text { Wire cerclage } \\
(n=100)\end{array}$ & $P$ value \\
\hline Sternal healing score & $2.6 \pm 1.1$ & $1.8 \pm 1.0$ & $<0.0001$ & $3.8 \pm 1.0$ & $3.3 \pm 1.1$ & 0.0007 \\
\hline Sternal union rate & $40.8 \%(42 / 103)$ & $15.7 \%(16 / 102)$ & $<0.0001$ & $80.2 \%(81 / 101)$ & $67.0 \%(67 / 100)$ & 0.03 \\
\hline
\end{tabular}

Table 4 Predictors of sternal healing scores

\begin{tabular}{|c|c|c|c|c|c|c|}
\hline Covariates $^{2}$ & \multicolumn{3}{|c|}{3 months regression ${ }^{1}$} & \multicolumn{3}{|c|}{6 months regression ${ }^{1}$} \\
\hline Rigid plate fixation & $0.79 \pm 0.14$ & $<0.0001$ & 0.52 to 1.07 & $0.45 \pm 0.14$ & 0.002 & 0.17 to 0.73 \\
\hline Higher BMI (per 5 kg/m²) & $-0.20 \pm 0.07$ & 0.008 & -0.35 to -0.05 & $-0.28 \pm 0.08$ & $<0.001$ & -0.43 to -0.13 \\
\hline Older age (per 10 years) & $-0.15 \pm 0.06$ & 0.012 & -0.26 to -0.03 & $-0.20 \pm 0.06$ & 0.001 & -0.32 to -0.09 \\
\hline \multicolumn{7}{|c|}{$\begin{array}{l}\text { Notes: }{ }^{1} \text {, backwards stepwise regression with } \mathrm{P}<0.05 \text { to stay; }{ }^{2} \text {, the following were also included in the initial models but were sequentially } \\
\text { removed as not incrementally significant }(\mathrm{P}>0.05) \text { in both models at both time points by the backwards stepwise procedures: peripheral } \\
\text { artery disease, chronic lung disease, male gender, race, or time (hours), hypertension, cerebrovascular disease, diabetes, previous } \\
\text { sternotomy, CABG, valve, and closure time (minutes). Diabetes was closely correlated with higher BMI. BMI, body mass index; CABG, } \\
\text { coronary artery bypass graft. }\end{array}$} \\
\hline
\end{tabular}

significantly less in patients randomized to RPF compared to WC $[0 \%(0 / 116)$ vs. $5 \%(6 / 120) ; \mathrm{P}=0.03]$, with a trend towards fewer sternal wound infections $[0 \%(0 / 116) v s .4 .2 \%$ (5/120); $\mathrm{P}=0.06]$. Half of all reported sternal complications in this series occurred beyond the traditional 30-day reporting period. The in-hospital/30-day DSWI rate was $0 \%(0 / 116)$ with RPF compared with $1.7 \%$ (2/120) with WC. Sternal complications in the WC group resulted in six readmissions between postoperative day 8 and 169 and resulted in an additional 94 days of hospital stay, 11 reoperations, and one death.

Sternal closure with WC was the only predictor of sternal complications [odds ratio $(\mathrm{OR}), 11.5 ; \mathrm{P}=0.02$ ] and sternal wound infections $(\mathrm{OR}, 10.7 ; \mathrm{P}=0.03)$. Although $\mathrm{BMI}$ was not an independent predictor of sternal complications, there was a trend with increasing BMI for both increased sternal complications (OR 1.2 per unit increase BMI; $\mathrm{P}=0.10)$ and wound infections (OR 1.2 per unit increase $\mathrm{BMI} ; \mathrm{P}=0.07$ ) in the WC group (Figure 3).

\section{Patient reported outcome measures}

Pain scores both at rest and after forced coughing were numerically lower (i.e., less pain) with RPF compared to WC at each follow-up timepoint. More patients in the $\mathrm{RPF}$ group reported no sternal pain at rest at both 6 weeks $(\mathrm{P}=0.02)$ and 3 months $(\mathrm{P}=0.03)$ and no sternal pain after forced coughing at 3 weeks $(\mathrm{P}=0.001)$ and 6 weeks $(\mathrm{P}=0.005)$ compared to $\mathrm{WC}$ patients. Logistic regression analysis demonstrated a significant correlation between better sternal healing and reduced postoperative pain (Figure 4). For each unit of increase in the patient's CT scan healing score, the odds of being pain free increased by $60 \%$ both at rest $(\mathrm{OR}=1.6 ; 95 \% \mathrm{CI}: 1.2-2.2 ; \mathrm{P}=0.002)$ and after forced coughing $(\mathrm{OR}=1.6$; $\mathrm{CI}: 1.2-2.2 ; \mathrm{P}=0.0007)$.

QOL physical and mental component summary scores were numerically higher (i.e., better) with RPF at all follow-up time points with significant differences in favor of RPF for the physical component score at 6 weeks (mean difference $=2.6$ points; $\mathrm{P}=0.03$ ) and for the mental component score at 3 weeks (mean difference $=3.0$; $\mathrm{P}=0.03$ ) and 6 months (mean difference $=2.5 ; \mathrm{P}=0.04$ ). Mean scores on the UEFI were numerically better after RPF compared with WC at all measured time points; however, the differences were only statistically significant at 6 weeks (67.6 \pm 14.5 vs. $62.0 \pm 17.1 ; \mathrm{P}=0.02)$. In contrast, the probability 


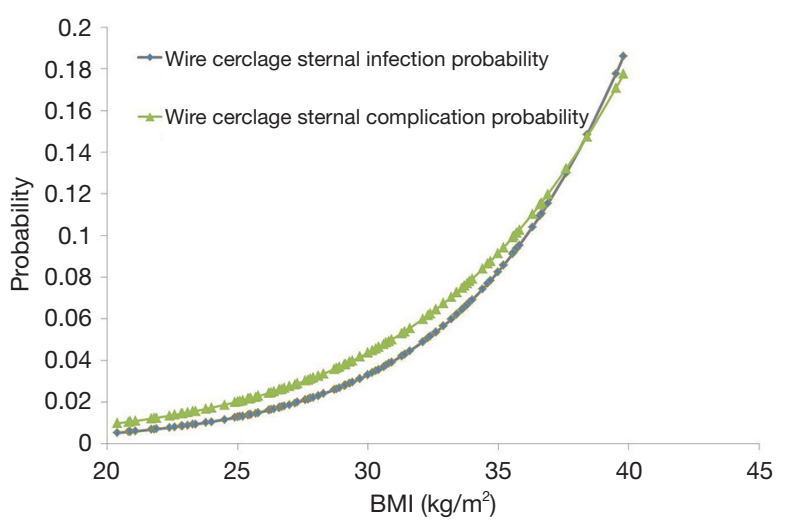

Figure 3 Wire cerclage predicted probability of a sternal complication and infection with increasing body mass index.

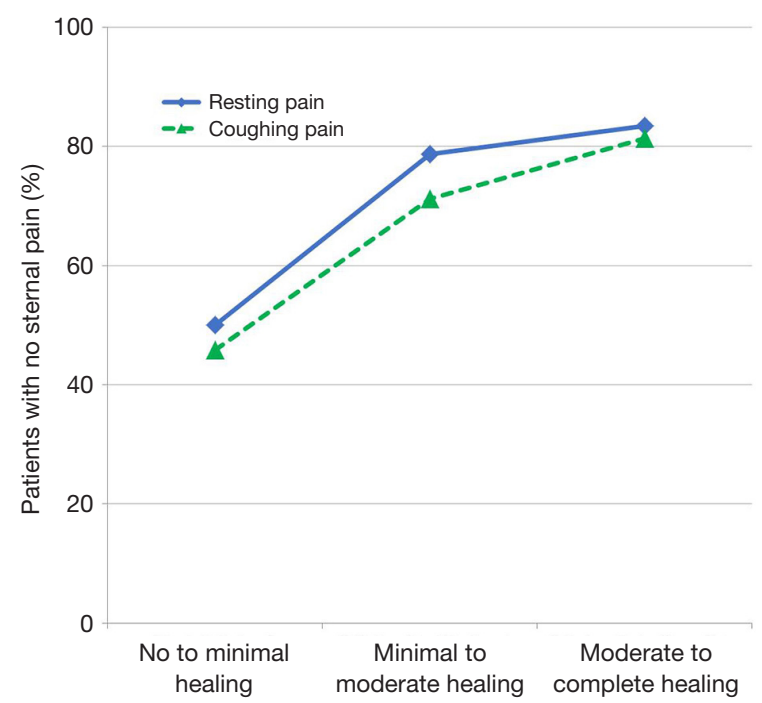

Figure 4 The percentage of patients free of sternal pain as a function of healing. Computed tomography scores were aggregated to represent no to minimal healing (scores from 0 to 2), minimal to moderate healing ( 2 to 4 ), and moderate to complete healing (4 to 5).

\begin{tabular}{llll}
$\begin{array}{l}\text { Table 5 Proportion of upper extremity functional index (UEFI) } \\
\text { scores indicating patients had no difficulty with using their upper } \\
\text { extremities }\end{array}$ \\
\hline Follow-up interval & $\begin{array}{l}\text { Rigid plate } \\
\text { fixation (\%) }\end{array}$ & $\begin{array}{l}\text { Wire cerclage } \\
(\%)\end{array}$ & P value \\
\hline 3 weeks & 49.6 & 39.9 & $<0.0005$ \\
\hline 6 weeks & 69.8 & 58.8 & $<0.0005$ \\
3 months & 82.0 & 77.8 & 0.004 \\
6 months & 85.4 & 81.6 & 0.006 \\
\hline
\end{tabular}

of a patient reporting no difficulty with UEF was significantly better with RPF at all follow-up time points (Table 5).

\section{Health economic endpoints}

Initial hospital costs assessed from the time of sternal closure through discharge trended higher with RPF $(\$ 2,800 /$ patient higher; $\mathrm{P}=0.11$ ), driven primarily by the initial cost of sternal plates and screws. Following discharge, however, healthcare costs trended lower with RPF compared to WC through 90 days $(\$ 4,700 /$ patient lower; $\mathrm{P}=0.06)$ and 180 days ( $\$ 4,500 /$ patient lower; $\mathrm{P}=0.14)$. The cost reduction during follow-up with RPF patients was driven by fewer sternal complications, fewer readmissions, and fewer days in rehabilitation hospitals and skilled nursing facilities. Total healthcare costs are detailed in Table 6 and were $\$ 1,888$ less at 90 days in RPF patients compared to WC patients ( $\$ 29,179$ vs. $\$ 31,067 ; 95 \%$ CI: $-\$ 8,889$ to $\$ 4,273 ; \mathrm{P}=0.52$ ) and $\$ 1,646$ less at 6 months $(\$ 32,439$ vs. $\$ 34,085 ; 95 \% \mathrm{CI}$ : $-\$ 9,127$ to $\$ 4,706 ; \mathrm{P}=0.61)$.

\section{Discussion}

In a multicenter, prospective, randomized controlled trial, $\mathrm{RPF}$ when compared to $\mathrm{WC}$, resulted in significantly better sternal healing by $\mathrm{CT}$ at 3 months $(2.6 \pm 1.1$ vs. $1.8 \pm 1.0$; $\mathrm{P}<0.0001)$ and 6 months $(3.8 \pm 1.0$ vs. $3.3 \pm 1.1 ; \mathrm{P}=0.0007)$ and significantly fewer sternal complications at 6 months $[0 \%$ (0/116) vs. 5\% (6/120); $\mathrm{P}=0.03$ ] (9). Additional secondary endpoints from this RCT demonstrated that RPF also significantly reduced postoperative pain, improved UEF, and improved QOL scores at several time points during the 6-month follow-up period (15). When healthcare costs were analyzed through 90 and 180 days follow up, these important patient benefits were achieved with no additional cost to the healthcare system $(9,15)$.

Successful fracture management relies on bony approximation, compression, and stabilization for proper bone healing to occur. Although WC provides lateral reduction during sternotomy closure, it fails to provide adequate stabilization to optimize sternal healing $(6,12,23)$. Biomechanical studies have demonstrated that regardless of wiring technique, RPF provides superior stability $(4,5,8)$. Raman and colleagues evaluated sternal healing with CT in a prospective RCT comparing $\mathrm{WC}$ with a first-generation RPF system (SternaLock, Zimmer Biomet, Jacksonville, FL) and demonstrated better sternal healing with RPF (12). We confirmed these findings using the same CT methodology 


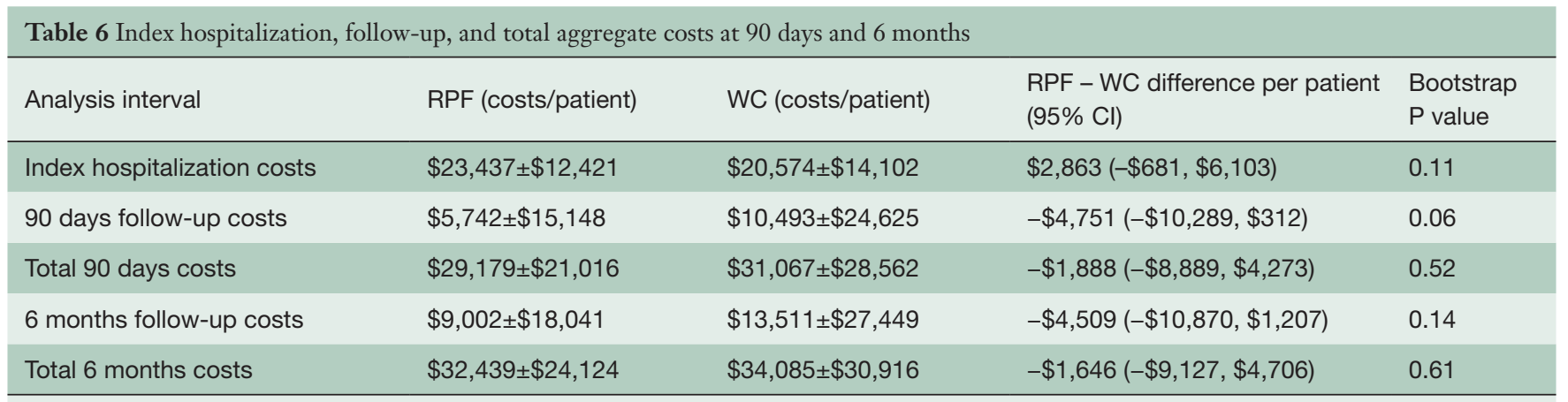

RPF, rigid plate fixation; WC, wire cerclage.

with a second-generation RPF system and further correlated this radiographic endpoint with the more clinically meaningful endpoint of fewer sternal complications.

Sternal complication rates after cardiac surgery, which include superficial and deep infections, range from $0.7 \%$ to $11.1 \%$ (24-30). These studies, which include both prospective and retrospectively collected data, encompass variable lengths of follow-up ranging from 30 days to 1 year. Databases that track outcomes only to 30 days (such as that kept by the STS) are likely to underreport sternal complication rates, leading to the current perception held by many cardiac surgeons that sternal complication rates are low and that $\mathrm{WC}$ is adequate. In a prospective study involving more than 7,000 patients, Allen and colleagues reported that the median time to diagnose a DSWI/ bacteremia infection after cardiac surgery was postoperative day 40, which was beyond the typical 30-day reporting period (31). Consistent with previous studies, we reported an overall sternal complication rate after WC through 6 months of $5 \%(2.5 \%$ at 30 days $)$, which included a 6-month DSWI rate of $2.5 \%$ (1.7\% at 30 days), with no sternal complications reported in the RPF group. These sternal complications represent significant morbidity and cost despite being relatively uncommon events. In this study, the average cost for rehospitalization for a sternal complication was $\$ 45,532$ and comparable with the $\$ 62,000$ cost reported by Lazar and colleagues (27). The use of RPF mitigated traditional risk factors for sternal complications, with WC being the only independent predictor of both sternal complications and infections. The use of enhanced sternal stabilization to potentially reduce the risk of sternal infections, particularly in high-risk patients, recently was recognized by the STS Practice Guidelines and an expert consensus by Lazar and colleagues, where it was given a Level IIB recommendation $(27,32)$.
While sternal complications are of unquestioned clinical relevance, PROMs such as the ability to resume normal activities following surgery and postoperative pain are increasingly scrutinized by payors. RPF provides earlier and better sternal stability compared to WC, which independent of bone healing, leads to significant improvements in PROMs. These improvements were seen during the first 3 months after surgery when the number of patients with sternal union is limited ( $41 \%$ of RPF patients $v s .16 \%$ of WC patients; $\mathrm{P}<0.0001$ ), suggesting that the immediate postoperative stability provided by RPF plays an important role in mitigating sternal pain and improving UEF (9).

There is increasing interest in episode payment models (EPM) for cardiac surgery in the United States whereby hospitals are responsible for the cost over longer time periods. In 2015, Congress passed the Medicare Access and Children's Health Insurance Program Reauthorization Act (MACRA) and established alternative payment models (APMs) and the Merit-based Incentive Payment System (MIPS). In the proposed 90-day bundle for isolated CABGs, hospitals that meet quality and cost targets would benefit financially, whereas those that failed would be penalized (33). Under such payment models, the use of RPF would be highly favored, given the improvements in clinical outcomes that were achieved without an increase in 90-day or 6-month cost. Important lessons can be learned from early participants in bundled payment models. Engelman noted that incorporating protocols or treatments that reduce readmissions and effectively reduce post-acute disposition to extended care facilities were the two biggest variables in affecting a positive margin in their bundle (34). The use of RPF in this trial resulted in a trend towards reducing readmission rates and less time spent in rehabilitation hospitals and skilled nursing facilities.

There are several limitations to the current study. 
One limitation was the inability to consistently blind the radiologists reading the $\mathrm{CT}$ scans as to treatment group allocation. Attempts were made to minimize bias by having one radiologist select $\mathrm{CT}$ slices that did not reveal the method of sternal closure. Another limitation was the $11.4 \%(27 / 236)$ lost to follow-up rate at 6 months. Despite this, the primary endpoint remained appropriately powered and positive with a sample size calculation that allowed for an $18 \%$ attrition rate. While this study (like most RCT's) was not sufficiently powered for the secondary endpoints, the consistent improvements in these outcomes with RPF compared to WC at each follow-up are supportive. Finally, whether the positive results from this study can be generalized to other RPF systems is unknown. Only two RCTs comparing RPF to WC have been done to date, and since both studies used first (12) and second-generation devices $(9,15)$ from the same manufacturer, conclusions on the class effect of RPF systems cannot be made.

In conclusion, in a prospective, randomized, multicenter trial, sternotomy closure using RPF compared to WC resulted in improved sternal healing, fewer sternal complications, and improved PROMs while remaining cost neutral at both 3 and 6 months follow up $(9,15)$. Economically dominant technology, like RPF, that improves outcomes without increasing costs will become increasingly important as the focus of healthcare shifts from the index admission/30-day period to a global episodic payment model.

\section{Acknowledgements}

The study was sponsored and funded by Zimmer Biomet, Inc. (Jacksonville, FL), the sponsor participated in study design, data collection and analysis, however, the authors had full control of study, methods used, outcome parameters and results, analysis of data, and production of the manuscript. Statistical analysis was performed by Greg Maislin (Biomedical Statistical Consulting). Scott Stacy, MD (University of Chicago) oversaw the radiologic core laboratory. Kaijun Wang, $\mathrm{PhD}$ and Katherine Vilain, MS participated in the health economic core laboratory analysis under the supervision of David Cohen, MD (St. Luke's Mid America Heart Institute).

\section{Footnote}

Conflicts of Interest: Drs. Allen, Gerdisch, and Icke disclose a financial relationship with Zimmer Biomet. The other authors have no conflicts of interest to declare.

\section{References}

1. Mozaffarian D, Benjamin EJ, Go AS, et al. Heart disease and stroke statistics--2015 update: a report from the American Heart Association. Circulation 2015;131:e29-322.

2. Uhthoff HK, Poitras P, Backman DS. Internal plate fixation of fractures: short history and recent developments. J Orthop Sci 2006;11:118-26.

3. El-Ansary D, Waddington G, Adams R. Measurement of Non-Physiological Movement in Sternal Instability by Ultrasound. Ann Thorac Surg 2007;83:1513-6.

4. Losanoff JE, Basson MD, Gruber SA, et al. Single wire versus double wire loops for median sternotomy closure: experimental biomechanical study using a human cadaveric model. Ann Thorac Surg 2007;84:1288-93.

5. Losanoff JE, Collier AD, Wagner-Mann CC, et al. Biomechanical comparison of median sternotomy closures. Ann Thorac Surg 2004;77:203-9.

6. Nishimura T, Kurihara C, Sakano Y, et al. Sternalock plating system for elderly post-sternotomy patients. J Artif Organs 2014;17:288-90.

7. Pai S, Gunja NJ, Dupak EL, et al. A mechanical study of rigid plate configurations for sternal fixation. Ann Biomed Eng 2007;35:808-16.

8. Pai S, Gunja NJ, Dupak EL, et al. In vitro comparison of wire and plate fixation for midline sternotomies. Ann Thorac Surg 2005;80:962-8.

9. Allen KB, Thourani VH, Naka Y, et al. Randomized, multicenter trial comparing sternotomy closure with rigid plate fixation to wire cerclage. J Thorac Cardiovasc Surg 2017;153:888-896.e1.

10. Lee JC, Raman J, Song DH. Primary sternal closure with titanium plate fixation: plastic surgery effecting a paradigm shift. Plast Reconstr Surg 2010;125:1720-4.

11. Park JS, Kuo JH, Young JN, et al. Rigid Sternal Fixation Versus Modified Wire Technique for Poststernotomy Closures: A Retrospective Cost Analysis. Annals of Plastic Surgery. 2017;78:537-42.

12. Raman J, Lehmann S, Zehr K, et al. Sternal closure with rigid plate fixation versus wire closure: a randomized controlled multicenter trial. Ann Thorac Surg 2012;94:1854-61.

13. Raman J, Song DH, Bolotin G, et al. Sternal closure with titanium plate fixation--a paradigm shift in preventing mediastinitis. Interact Cardiovasc Thorac Surg 2006;5:336-9. 
14. Song DH, Lohman RF, Renucci JD, et al. Primary sternal plating in high-risk patients prevents mediastinitis. Eur J Cardiothorac Surg 2004;26:367-72.

15. Allen KB, Thourani VH, Naka Y, et al. Rigid Plate Fixation Versus Wire Cerclage: Patient-Reported and Economic Outcomes From a Randomized Trial. Ann Thorac Surg 2018;105:1344-50.

16. Raman J, Straus D, Song DH. Rigid plate fixation of the sternum. Ann Thorac Surg 2007;84:1056-8.

17. Stacy G, Ahmed O, Richardson A, et al. Evaluation of sternal bone healing with computed tomography and a quantitative scoring algorithm. Open Medical Imaging Journal 2014;8:29-35.

18. Stratford P, Binkley J, Stratford D. Development and initial validation of the Upper Extremity Functional Index. Physiother Can 2001:259-67.

19. Cohen DJ, Bakhai A, Shi C, et al. Cost-effectiveness of sirolimus-eluting stents for treatment of complex coronary stenoses: results from the Sirolimus-Eluting Balloon Expandable Stent in the Treatment of Patients With De Novo Native Coronary Artery Lesions (SIRIUS) trial. Circulation 2004;110:508-14.

20. Reynolds MR, Lei Y, Wang K, et al. Cost-Effectiveness of Transcatheter Aortic Valve Replacement With a SelfExpanding Prosthesis Versus Surgical Aortic Valve Replacement. J Am Coll Cardiol 2016;67:29-38.

21. Reynolds MR, Magnuson EA, Lei Y, et al. Costeffectiveness of transcatheter aortic valve replacement compared with surgical aortic valve replacement in highrisk patients with severe aortic stenosis: results of the PARTNER (Placement of Aortic Transcatheter Valves) trial (Cohort A). J Am Coll Cardiol 2012;60:2683-92.

22. Efron B. An introduction to the bootstrap. New York, NY: Chapman \& Hall, 1993.

23. Matsuyama K, Kuinose M, Koizumi N, et al. Sternal closure by rigid plate fixation in off-pump coronary artery bypass grafting: a comparative study. J Artif Organs 2016;19:175-8.

24. Benedetto U, Altman DG, Gerry S, et al. Pedicled and skeletonized single and bilateral internal thoracic artery grafts and the incidence of sternal wound complications: Insights from the Arterial Revascularization Trial. J Thorac Cardiovasc Surg 2016;152:270-6.

25. Crabtree TD, Codd JE, Fraser VJ, et al. Multivariate analysis of risk factors for deep and superficial sternal infection after coronary artery bypass grafting at a tertiary care medical center. Semin Thorac Cardiovasc Surg
2004;16:53-61.

26. De Paulis R, de Notaris S, Scaffa R, et al. The effect of bilateral internal thoracic artery harvesting on superficial and deep sternal infection: The role of skeletonization. J Thorac Cardiovasc Surg 2005;129:536-43.

27. Lazar HL, Vander Salm T, Engelman R, et al. Prevention and management of sternal wound infections. J Thorac Cardiovasc Surg 2016;152:962-72.

28. Shahian DM, O'Brien SM, Filardo G, et al. The Society of Thoracic Surgeons 2008 cardiac surgery risk models: part 3--valve plus coronary artery bypass grafting surgery. Ann Thorac Surg 2009;88:S43-62.

29. Shahian DM, O'Brien SM, Filardo G, et al. The Society of Thoracic Surgeons 2008 cardiac surgery risk models: part 1--coronary artery bypass grafting surgery. Ann Thorac Surg 2009;88:S2-22.

30. Stelly MM, Rodning CB, Stelly TC. Reduction in deep sternal wound infection with use of a peristernal cable-tie closure system: a retrospective case series. J Cardiothorac Surg 2015;10:166.

31. Allen KB, Fowler VG Jr, Gammie JS, et al. Staphylococcus aureus Infections After Elective Cardiothoracic Surgery: Observations From an International Randomized PlaceboControlled Trial of an Investigational S aureus Vaccine. Open Forum Infect Dis 2014;1:ofu071.

32. Aldea GS, Bakaeen FG, Pal J, et al. The Society of Thoracic Surgeons Clinical Practice Guidelines on Arterial Conduits for Coronary Artery Bypass Grafting. Ann Thorac Surg 2016;101:801-9.

33. Centers for Medicare and Medicaid Services. Notice of proposed rulemaking for bundled payment models for high quality, coordinated cardiac and hip fracture care. Available online: https://www.cms.gov/Newsroom/ MediaReleaseDatabase/Fact-sheets/2016-Fact-sheetsitems/2016-07-25.html, accessed June 2, 2017.

34. Engelman DT. Surgical economics: MACRA, MIPS, and bundles-Lessons learned in the first 3 years of a coronary artery bypass grafting alternative payment model. J Thorac Cardiovasc Surg 2017;153:381-4.

Cite this article as: Allen KB, Icke KJ, Thourani VH, Naka Y, Grubb KJ, Grehan J, Patel N, Guy TS, Landolfo K, Gerdisch M, Bonnell M. Sternotomy closure using rigid plate fixation: a paradigm shift from wire cerclage. Ann Cardiothorac Surg 2018;7(5):611-620. doi: 10.21037/acs.2018.06.01 